\title{
Bovine Milk Lipoprotein Lipase Transfers Tocopherol to Human Fibroblasts during Triglyceride Hydrolysis In Vitro
}

\author{
Maret G. Traber, Thomas Olivecrona, and Herbert J. Kayden \\ Department of Medicine, New York University School of Medicine, New York 10016; University of Umea, Umea, Sweden
}

\begin{abstract}
Lipoprotein lipase appears to function as the mechanism by which dietary vitamin $E$ (tocopherol) is transferred from chylomicrons to tissues. In patients with lipoprotein lipase deficiency, more than $85 \%$ of both the circulating triglyceride and tocopherol is contained in the chylomicron fraction. The studies presented here show that the in vitro addition of bovine milk lipoprotein lipase (lipase) to chylomicrons in the presence of human erythrocytes or fibroblasts (and bovine serum albumin [BSA]) resulted in the hydrolysis of the triglyceride and the transfer of both fatty acids and tocopherol to the cells; in the absence of lipase, no increase in cellular tocopherol was detectable. The incubation system was simplified to include only fibroblasts, BSA, and Intralipid (an artificial lipid emulsion containing $10 \%$ soybean oil, which has gamma but not alpha tocopherol). The addition of lipase to this system also resulted in the transfer of tocopherol (gamma) to the fibroblasts. Addition of both lipase and its activator, apolipoprotein CII, resulted in a further increase in the cellular tocopherol content, but apoliprotein CII alone had no effect. Heparin, which is known to prevent the binding of lipoprotein lipase to the cell surface membrane, abrogated the transfer of tocopherol to fibroblasts without altering the rate of triglyceride hydrolysis. Thus, in vitro tocopherol is transferred to cells during hydrolysis of triglyceride by the action of lipase, and for this transfer of tocopherol to occur, the lipase itself must bind to the cell membrane.
\end{abstract}

\section{Introduction}

Vitamin E (alpha tocopherol) deficiency has been described in patients with various lipid malabsorption syndromes, including: abetalipoproteinemia $(1,2)$, cholestatic liver disease (3), and short bowel syndrome (4). In 1967, Kayden recommended dietary supplementation with vitamin $\mathrm{E}$ for patients with abetalipoproteinemia (2). The malabsorption syndrome in these genetically affected subjects is a result of their inability to synthesize apolipoprotein B; these patients are thus unable to secrete chylomicrons, very low or low density lipoproteins (VLDL or LDL, respectively). Patients with abetalipoproteinemia have low levels of circulating lipids, as well as low levels of plasma tocopherol, despite supplemental vitamin E (1). However, those patients, who have been supplemented with

This work has appeared in abstract form in 1984. Fed. Proc. 43:824. Address reprint requests to Dr. Kayden, Department of Medicine, New York University School of Medicine, New York 10016.

Received for publication $30 \mathrm{May} 1984$ and in revised form 28 January 1985.

J. Clin. Invest.

(c) The American Society for Clinical Investigation, Inc.

0021-9738/85/05/1729/06 \$1.00

Volume 75, May 1985, 1729-1734 vitamin E, have minimal or absent neurological abnormalities, but those who have not been supplemented have a progressive degeneration of the peripheral nervous system resulting in ataxia and characteristic pathologic changes in the central nervous system (5). These neuropathologic changes have been observed in patients with cholestatic liver disease in whom the low to absent levels of bile salts in the intestine results in an inability to absorb vitamin E (3). Oral supplementation with pharmacologic amounts of the vitamin (6), or parenteral administration of the vitamin (when there is a complete absence of intestinal bile) (7) results in the prevention of further deterioration of the nervous system. The studies in these two groups of patients have demonstrated the importance of bile acids and chylomicron formation for the absorption of dietary vitamin $\mathrm{E}$ and its transport in the plasma. The studies described in this report were undertaken in an effort to describe how tocopherol is transferred from the plasma to the tissues.

Tocopherol is present in normal individuals in all of the plasma lipoprotein fractions; no specific carrier has been reported for the vitamin (8). Previously, we have demonstrated that the tocopherol present in LDL or high density lipoprotein (HDL) readily transfers to erythrocytes, when incubated together in vitro (9). Furthermore, we have recently reported that the tocopherol present in LDL is delivered to fibroblasts via the high affinity receptor for LDL (10).

In contrast to the ease with which tocopherol can exchange when it is present in LDL or HDL, the tocopherol present in VLDL exchanged poorly in the experimental system (9). In patients who are deficient in lipoprotein lipase (type I), $>85 \%$ of the circulating tocopherol and triglyceride is confined to lipoproteins with densities $<1.006 \mathrm{~g} / \mathrm{ml}$, presumably chylomicrons and VLDL (1). Lipoprotein lipase is known to hydrolyze triglyceride to free fatty acids and transfer the fatty acids to tissues (for review, see 11). This enzyme can also mediate the transfer of cholesteryl esters (i2) or cholesteryl linoleyl ether (13) from triglyceride-rich lipoproteins to cells. Thus, we speculated that lipoprotein lipase might play a significant role in the distribution of tocopherol from chylomicrons to the tissues. We describe here our studies in tissue culture using chylomicrons (from type I patients) or Intralipid (an artificial lipid emulsion) as substrate for bovine milk lipoprotein lipase (lipase), and either human fibroblasts or human erythrocytes as acceptor cells.

\section{Methods}

Cell culture. Fibroblasts were obtained from the Genetic Cell Repository (Camden, NJ). The normal cells used were GM0144 and the cells of the homozygote for familial hypercholesterolemia were GM0486. Cells were grown in $20 \%$ fetal calf serum in Dulbecco's modified Eagle medium (DMEM) $)^{1}$ with penicillin and streptomycin at $37^{\circ} \mathrm{C}$ with $5 \%$

1. Abbreviations used in this paper: DMEM, Dulbecco's modified Eagle medium. 
$\mathrm{CO}_{2}$. Confluent monolayers of cells in $25 \mathrm{~cm}^{2}$ flasks were used for the incubations, which are described below.

Isolation of chylomicrons. Patients with hypertriglyceridemia (serum triglycerides in excess of $1,000 \mathrm{mg} / \mathrm{dl}$ ), normal levels of apolipoprotein CII, and absent lipoprotein lipase activity after intravenous injection of heparin were donors of "chylomicrons." Plasma $(30 \mathrm{ml})$ from each patient was isolated from whole blood, then spun without change in density for $1 \mathrm{~h}$ at $100,000 \mathrm{~g}$. The $d<1.006 \mathrm{~g} / \mathrm{ml}$ layer was isolated, and is called "chylomicrons" for the purposes of these experiments.

Preparation of erythrocytes. Erythrocytes were isolated from whole blood donated by normal volunteers by centrifugation for $10 \mathrm{~min}$ at 2,000 rpm. The plasma and buffy coat were discarded and the erythrocytes washed three times with phosphate-buffered saline, $\mathrm{pH}$ 7.4, as previously described (14).

Preparation of radioactive intralipid. Glyceryl-tri(stearate $9,10-{ }^{3} \mathrm{H}$ ) (Nuclear Chicago Corp., Des Plaines, IL) was plated onto silica gel G, the plate developed in petroleum ether/ethyl ether/acetic acid (83:16: 1), the triglyceride fraction identified, and the silica gel scraped and extracted with chloroform. An aliquot of the chloroform containing $\sim 2 \times 10^{8} \mathrm{cpm}$ was dried down in a scintillation vial, then $\sim 5 \mathrm{ml}$ Intralipid was added, and the sample stirred overnight at room temperature. Approximately $10 \%$ of the radioactivity was exchanged onto the Intralipid by this procedure.

Bovine milk lipoprotein lipase. The lipase was isolated as described previously (15). It was kept frozen at $-60^{\circ} \mathrm{C}$ and defrosted on ice immediately before use.

Cell incubation protocol. Fibroblasts (washed once in the flask with DMEM) or erythrocytes (isolated as described above) were incubated for $1 \mathrm{~h}$ with chylomicrons with or without lipase in the presence of 7.5\% bovine serum albumin (BSA) in DMEM at pH 7.4 for Table I. For Fig. 1, the standard protocol (described below) was used with the addition of chylomicrons.

The standard protocol was carried out with defined components. Fibroblasts were washed, then $1 \mathrm{ml}$ of DMEM was added to the flask, followed by $3 \mathrm{ml}$ substrate (radioactive Intralipid [ $1 \mathrm{ml} / 3 \mathrm{ml}$ substrate] in DMEM with BSA; final BSA concentration was $4 \%$, i.e., $160 \mathrm{mg} / 4$ $\mathrm{ml})$. In the studies where heparin (1,000 USP units/ml; O'Neal, Jones \& Feldman, St. Louis, MO) and/or apolipoprotein CII (a gift from Richard Jackson, University of Cincinnati College of Medicine, Cincinnati, $\mathrm{OH}$ ) were included in the incubation system, each was added after the substrate, but before the lipase. The apolipoprotein CII was added in a total volume of $50 \mu \mathrm{l}$ of guanidine buffer (6 M guanidine $\mathrm{HCl}, 10 \mathrm{mM}$ Tris, $\mathrm{pH} \mathrm{8.0)}$; the guanidine buffer was also added without apolipoprotein CII to all flasks in those experiments where the effect of apolipoprotein CII was studied. The amount of apolipoprotein CII used was $160 \mu \mathrm{g}, 20$ times the amount of lipase, as has previously been described using an incubation system with Intralipid (16). The amounts of heparin used were as described by Chajek-Shaul et al. (13).

Following the addition of all of the components to the flasks, the frozen bovine milk lipoprotein lipase was defrosted on ice, then immediately diluted with Intralipid (the total amount of Intralipid added was $1 \mathrm{ml} /$ flask; a portion was reserved when making the substrate for the dilution of the Intralipid), and aliquoted into the flasks containing cells and substrate. The flasks were placed in the dark in a shaker at $100 \mathrm{rpm}$ and incubated at room temperature for 1 h. At the end of the incubation, the medium was poured off and analyzed for the extent of triglyceride hydrolysis (see below), and the cells were analyzed for their tocopherol and protein contents (see below).

Tocopherol in cells. To prevent destruction of the tocopherol, all of the following procedures were carried out under subdued light. Fibroblasts were washed thoroughly with ice-cold buffer C (50 mM Tris, $0.15 \mathrm{M} \mathrm{NaCl}, 2 \mathrm{mg} / \mathrm{ml} \mathrm{BSA}$ ), then with buffer D (C without BSA), and were scraped from the flasks (17). The same buffers were used to wash erythrocytes, except the erythrocytes were washed with an equal volume of buffer by inverting the tube; then the tube was centrifuged briefly, the excess buffer removed, and the hematocrit measured. Aliquots of the cells were taken for the determination of protein by the method of Lowry et al. (18), for scintillation counting to measure the uptake of labeled fatty acids, and for measurement of tocopherol content following saponification (19). Briefly, the cells were saponified at $70^{\circ} \mathrm{C}$ with alcoholic $\mathrm{KOH}$ in the presence of $1 \%$ ascorbic acid for $\mathbf{3 0 ~ m i n , ~ t h e n ~ e x t r a c t e d ~ w i t h ~ h e x a n e . ~ T h e ~ h e x a n e ~ w a s ~ a l i q u o t e d , ~}$ dried down, and the residue dissolved in methanol with $1 \%$ ascorbic acid. The alpha and gamma tocopherol contents of the methanol were measured by injecting the methanol using the Waters Intelligent Sample Processor into the high performance liquid chromatography system, and detected by fluoresence (excitation, $205 \mathrm{~nm}$; emission, $340 \mathrm{~nm}$ ) as described previously (19). As little as $1 \mathrm{ng}$ of either alpha or gamma tocopherol could be measured accurately following this protocol.

Triglyceride hydrolysis. For the measurement of the free fatty acid content of the medium, the medium was poured directly into $15 \mathrm{ml}$ of stopping solution (heptane/chloroform/methanol [1:1.25:1.4] containing $\left[{ }^{14} \mathrm{C}\right]$ oleic acid, $\sim 8 \times 10^{6} \mathrm{cpm} / \mathrm{ml}$ ), and shaken vigorously for $1 \mathrm{~min}$, as described by Belfrage and Vaughan (20). Then, $1 \mathrm{ml}$ of $1 \mathrm{~N}$ $\mathrm{NaOH}$ was added, and the samples were shaken for $1 \mathrm{~h}$. At the end of the extraction period, the tubes were spun in a centrifuge for 10 min at $2,500 \mathrm{rpm}$ to separate the two layers. An aliquot $(6 \mathrm{ml})$ of the upper methanol/water layer was acidified with $100 \mu \mathrm{l}$ concentrated $\mathrm{HCl}$, and then extracted with heptane $(6 \mathrm{ml})$ by shaking for $1 \mathrm{~h}$. Following the extraction period, $2.5 \mathrm{ml}$ of $50 \%$ TCA was added, and then the tubes spun as before. (The TCA is added to precipitate the large amounts of albumin present, which otherwise remained at the heptane/methanol interface. Any fatty acids which might be trapped by the TCA are corrected for by the recovery of the internal standard.) Aliquots of the heptane were taken for counting $(100 \mu \mathrm{l})$ and for methylation $(5 \mathrm{ml})$.

To methylate the samples, the heptane was dried down and $0.5 \mathrm{ml}$ of $5 \% \mathrm{H}_{2} \mathrm{SO}_{4}$ in methanol with $1 \%$ benzene was added and the samples incubated overnight at $60^{\circ} \mathrm{C}$. The methyl esters of the fatty acids were then extracted with petroleum ether and aliquoted for counting (for recovery of the ${ }^{14} \mathrm{C}$ ) and for fatty acid quantitation, such that the samples contained between 0.5 and $2.0 \mu \mathrm{mol}$ fatty acid, and then the samples were dried down. $3 \mathrm{ml}$ of alcohol/ether (3:1) was added to each of the dried samples and $0.5 \mathrm{ml}$ of $2 \mathrm{M}$ hydroxylamine and 0.5 $\mathrm{ml} 3.5 \mathrm{~N} \mathrm{NaOH}$ were added; following vigorous mixing, the samples were allowed to stand $20 \mathrm{~min}$ at room temperature. Then, $0.6 \mathrm{ml}$ of $4 \mathrm{~N} \mathrm{HCl}$ and $0.5 \mathrm{ml}$ of $0.37 \mathrm{M} \mathrm{FeCl}_{3}$ in $0.1 \mathrm{~N} \mathrm{HCl}$ were added. The optical density of the product of this color reaction was measured using a Gilford Spectrophotometer (Gilford Instrument Laboratories, Oberlin, $\mathrm{OH})$ at $525 \mathrm{~nm}(21)$.

The amount of fatty acids hydrolyzed was quantitated from both the radioactive counts and from the hydroxylamine assay for the Intralipid samples and from the hydroxylamine assay alone for the chylomicron studies.

\section{Results}

Incubation of chylomicrons with lipase in the presence of cells resulted in a marked increase in the tocopherol content of the acceptor cells; erythrocytes had nearly a $60 \%$ increase in tocopherol content, while fibroblasts expressed a 35-fold increase (Table I). Erythrocytes incubated for $1 \mathrm{~h}$ with chylomicrons, in the absence of lipase, had a lower tocopherol content than the freshly isolated erythrocytes (1.81 compared with 2.56 $\mathrm{nmol} / \mathrm{ml}$ packed cells), presumably due either to the tocopherol being destroyed during the incubation, or the tocopherol transferring from the erythrocytes to the chylomicrons. However, fibroblasts incubated with chylomicrons in the absence of lipase contained the same amount of tocopherol as those cells that had not been incubated with chylomicrons (data not shown). Both erythrocytes and fibroblasts were used as the acceptors of tocopherol in preliminary experiments, but fre- 
Table I. Transfer of Alpha Tocopherol from Chylomicrons to Cells During Lipolysis by Lipoprotein Lipase

\begin{tabular}{lllc}
\hline Cells & Lipase & Tocopherol content & $\begin{array}{c}\text { Fatty acid } \\
\text { released }\end{array}$ \\
\hline \multirow{3}{*}{ Erythrocytes } & & (nmol/ml packed cells) & $\mu$ mol \\
& - & 1.81 & 0.5 \\
& + & 2.86 & 9.4 \\
Fibroblasts & & & \\
& & (nmol/mg protein) & \\
& + & 0.001 & $<0.5$ \\
& + & 1.22 & 8.7
\end{tabular}

The averages of duplicate incubations are shown. The tocopherol contents of the cells were measured following a 1-h incubation with chylomicrons (36.5 nmol tocopherol, $19.8 \mu \mathrm{mol}$ fatty acid) in the presence or absence of bovine milk lipoprotein lipase $(5 \mu \mathrm{g})$. The incubation medium was the same for both cell types-7.5\% BSA in DMEM, pH 7.4. The triglyceride hydrolysis was measured as free fatty acid released as described in Methods.

quently the hydrolysis of triglyceride resulted in the production of such large quantities of free fatty acids that hemolysis of the erythrocytes occurred in some experiments. Therefore, fibroblasts were used for the remaining experiments; however, it should be noted that the tocopherol content of erythrocytes was also increased by the action of lipoprotein lipase.

Since the increase in cellular tocopherol could be due to the apolipoproteins present on the chylomicrons functioning to transfer tocopherol, the lipase itself transferring the tocopherol, or as a result of the tocopherol in the chylomicron becoming exposed to the surface where it could transfer to cells, experiments were carried out in an incubation system with defined components. Intralipid, an artificial emulsion of triglycerides primarily from soybean oil, which does not contain apolipoproteins, was used as a substrate in place of the chylomicrons. (There is no alpha tocopherol present in this emulsion, only gamma tocopherol.) The emulsion was labeled with tri $\left[{ }^{3} \mathrm{H}\right]$ stearin by exchange, no solvent carriers were used; this allowed more rapid measurement of triglyceride hydrolysis. When both Intralipid and chylomicrons were simultaneously present in excess in the incubation system, the addition of increasing amounts of lipoprotein lipase resulted in the transfer of both alpha and gamma tocopherol to fibroblasts (Fig. 1);

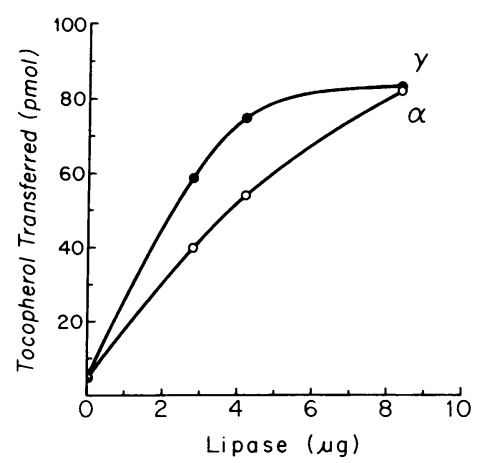

Figure 1. Lipoprotein lipase transfers both alpha and gamma tocopherols to fibroblasts. The averages of the cellular tocopherol contents of duplicate flasks of fibroblasts, which were incubated for $1 \mathrm{~h}$ with both chylomicrons ( $33 \mathrm{nmol}$ alpha tocopherol) and Intralipid (100 nmol gamma tocopherol) in the presence of 4\% BSA with increasing amounts of lipase, are

shown. Cells were washed and the tocopherol contents measured as described in Methods. gamma tocopherol transferred to the cells at least as well as alpha tocopherol at all levels of lipase tested.

Fig. 2 shows the results of a representative experiment in which Intralipid served as the sole source of both triglycerides and tocopherol: $2 \mathrm{~A}$ shows the amount of gamma tocopherol transferred to cells, $2 B$ shows the fatty acids transferred (determined from the radioactivity present in the cells), $2 C$ shows the hydrolysis of triglyceride, expressed as fatty acid released (determined from the radioactivity in the free fatty acids extracted from the medium). The tocopherol content of cells, fatty acids transferred and fatty acids released were all observed to increase with the addition of increasing amounts of lipoprotein lipase added to the incubation system, demonstrating that the transfer of tocopherol to cells occurred in the absence of apolipoproteins.

As apolipoprotein CII is an activator of the lipoprotein lipase enzyme, its effect on tocopherol transfer was tested in the incubation system. The simultaneous addition of both lipase and apolipoprotein CII to the medium resulted in a nearly sixfold increase in the tocopherol transferred compared with the transfer due to incubation with lipase alone (Table II). In the absence of lipase, or with the addition of apolipoprotein CII alone, no gamma tocopherol was transferred to the cells. Under these incubation conditions, the addition of apolipoprotein CII increased the triglyceride hydrolysis by $15 \%$, but decreased the rate of free fatty acid transfer compared with those cells incubated with lipase alone. Thus, apolipoprotein CII promotes the transfer of tocopherol to cells, but does not transfer tocopherol by itself.

Lipoprotein lipase is known to bind to cell membranes; heparin inhibits this binding (13). To test whether the transfer of gamma tocopherol to cells required the binding of the lipase to the cell membrane, heparin was added (before the lipase) to the incubation medium, the cells were incubated for $1 \mathrm{~h}$ with the lipase and the Intralipid substrate and then washed, and the amount of cellular tocopherol was measured. Both

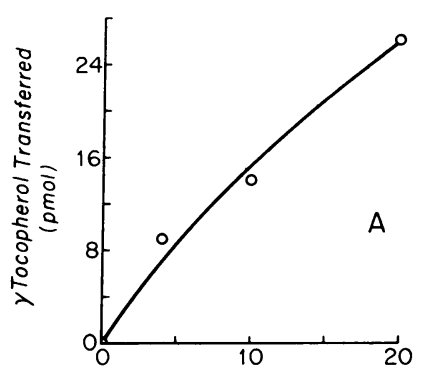

Figure 2. Increasing amounts of lipoprotein lipase result in increasing amounts of tocopherol and fatty acid transferred to

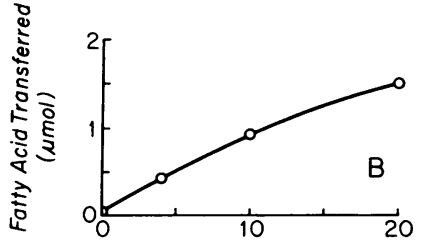
cells. Duplicate incubations containing Intralipid ( $120 \mathrm{nmol}$ tocopherol, $270 \mu \mathrm{mol}$ fatty acid), $4 \%$ BSA (160 mg), and fibroblasts were carried out. Following washing, the fibroblasts were analyzed for cellular tocopherol $(A)$ and cellular fatty acid radioactivity $(B)$, and the medium was analyzed for triglyceride hydrolysis (expressed as fatty acids released from the radioactive triglyceride) $(C)$, as described in Methods.

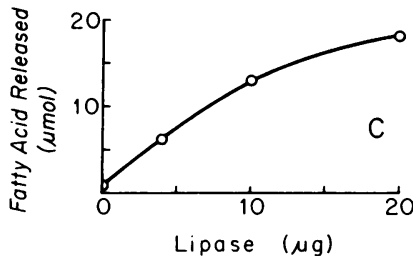

Lipoprotein Lipase Transfers Tocopherol to Cells 
Table II. Apolipoprotein CII Promotes Gamma

Tocopherol Transfer to Fibroblasts During

Lipolysis of Intralipid by Lipoprotein Lipase

\begin{tabular}{llll}
\hline & & \multicolumn{2}{l}{ Free fatty acids } \\
\cline { 4 - 4 } Additions & $\begin{array}{l}\text { Tocopherol } \\
\text { transferred }\end{array}$ & Transferred & Released \\
\hline & pmol & $\mu m o l$ & $\mu m o l$ \\
None & 0 & 0.03 & 2.5 \\
CII & 0 & 0.04 & 2.9 \\
Lipase & $6.2 \pm 1.8$ & 0.63 & 7.6 \\
Lipase + CII & $37.7 \pm 3.1$ & 0.35 & 9.0 \\
\hline
\end{tabular}

The averages of triplicate incubations are shown. Fibroblasts were incubated for $1 \mathrm{~h}$ with tri $\left[{ }^{3} \mathrm{H}\right]$ stearin-labeled Intralipid (130 $\mathrm{nmol}$ tocopherol, $330 \mu \mathrm{mol}$ fatty acid) and 4\% BSA in DMEM with the indicated additions of lipase $(8 \mu \mathrm{g})$ and/or apolipoprotein CII $(160 \mu \mathrm{g})$. The apolipoprotein CII was added in a total volume of $50 \mu \mathrm{l}$ of gua-

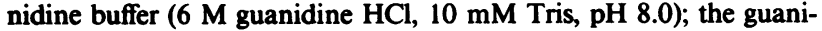
dine buffer was also added without apolipoprotein CII to all of the other flasks. The cells were thoroughly washed, and then the tocopherol contents, cellular radioactivity, and protein contents were measured as described in Methods. The amount of fatty acids released was calculated from the triglyceride radioactivity released into the medium as free fatty acids as described in Methods.

normal fibroblasts and LDL receptor-negative fibroblasts from a subject with the homozygous form of familial hypercholesterolemia were tested using this protocol; the results were similar in both types of fibroblasts. The data shown in Fig. 3 is from the $\mathrm{LDL}$ receptor-negative fibroblasts. In the absence of heparin, the amount of tocopherol transferred was the same
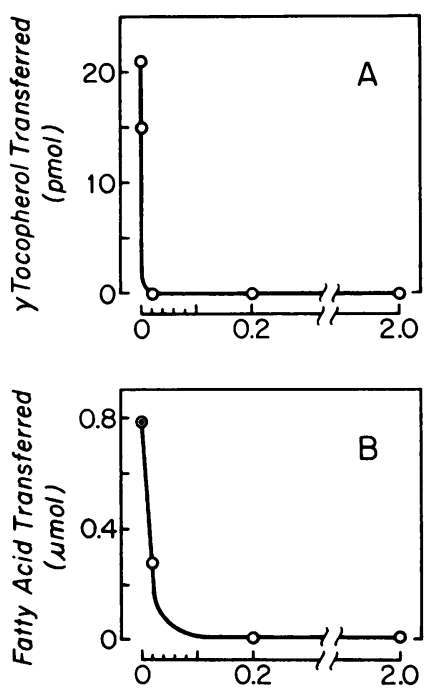

Figure 3. Addition of heparin to the incubation system abrogates the transfer of tocopherol to cells. Before the addition of lipase $(8 \mu \mathrm{g})$, heparin, in the indicated amount, was added to the incubation system (4 $\mathrm{ml}$ ), which contained Intralipid (160 nmol gamma tocopherol, $330 \mu \mathrm{mol}$ fatty acid), $4 \% \mathrm{BSA}$ and $L D L$ receptor-negative fibroblasts (from a patient with the homozygous form of hypercholesterolemia). Following

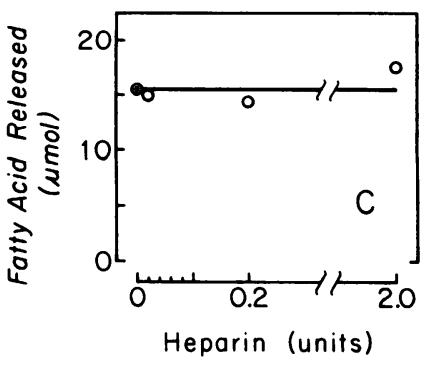
a 1-h incubation at room temperature, analysis of the cellular tocopherol $(A)$ and fatty acids, as radioactivity $(B)$, and the medium for the amount of triglyceride hydrolysis $(C)$ was carried out, as described in Methods. $\odot$ signifies two separate points too close to draw separately.
Table III. Heparin Inhibits the Transfer of Gamma Tocopherol to Cells During the Lipolysis of Intralipid in the Presence of Apolipoprotein CII

\begin{tabular}{lcll}
\hline & & \multicolumn{2}{l}{ Free fatty acids } \\
\cline { 4 - 4 } Additions & $\begin{array}{l}\text { Tocopherol } \\
\text { transferred }\end{array}$ & Transferred & Released \\
\hline & $p m o l$ & $\mu m o l$ & $\mu m o l$ \\
None & 0 & 0.22 & 3.3 \\
Lipase & 50.6 & 0.31 & 6.9 \\
Lipase + CII & 95.9 & 0.27 & 8.3 \\
Lipase + CII + heparin & 9.6 & 0.08 & 7.4 \\
& & & \\
\hline
\end{tabular}

The averages of results from duplicate incubations are shown. Fibroblasts were incubated for $1 \mathrm{~h}$ with Intralipid $(340 \mathrm{nmol}$ tocopherol, $330 \mu \mathrm{mol}$ fatty acid), $4 \%$ BSA $(160 \mathrm{mg} / 4 \mathrm{ml})$ with the additions shown: bovine milk lipoprotein lipase $(8 \mu \mathrm{g})$, apolipoprotein CII (160 $\mu \mathrm{g})$, and heparin $(0.2$ units). The apolipoprotein CII was added in a total volume of $50 \mu \mathrm{l}$ of guanidine buffer $(6 \mathrm{M}$ guanidine $\mathrm{HCl}, 10$ $\mathrm{mM}$ Tris, pH 8.0); the guanidine buffer was also added without apolipoprotein $\mathrm{CII}$ to all of the other flasks. The cells and medium were analyzed as described for Table II.

as that shown for normal fibroblasts incubated with $8 \mu \mathrm{g}$ lipase. The addition of as little as $\mathbf{0 . 0 2}$ units of heparin to the incubation medium was sufficient to abrogate the transfer of tocopherol. At this concentration of heparin, there was a measurable amount of fatty acid transferred, but this amount was $<40 \%$ of that transferred to those cells incubated without heparin. As shown in Fig. $3 C$, the rate of triglyceride hydrolysis was constant and was not affected by the presence of heparin in the incubation mixture at any of the concentrations of heparin used. Therefore, for tocopherol to transfer to cells, the lipase must bind to the cell membrane. It is apparent that the presence of the products of hydrolysis or the changes in conformation of the remnants of the lipid droplet are not sufficient for the transfer of tocopherol.

The inhibitory effect of heparin on the transfer of tocopherol could not be overcome by stimulating the lipase activity by the addition of apolipoprotein CII. As shown in Table III, although the simultaneous addition of lipase with apolipoprotein CII to the incubation system with normal fibroblasts resulted in the transfer of $95 \mathrm{pmol}$ of tocopherol to the cells, the addition of heparin to the incubation system, followed by the simultaneous addition of lipase and apolipoprotein CII, resulted in $9.6 \mathrm{pmol}$ transferred, a nearly 10 -fold decrease in the transfer of tocopherol to the cells. (It should be noted that the higher amount of tocopherol transferred shown in Table III as compared with the data in Table II was due to two different batches of Intralipid used for the two experiments).

\section{Discussion}

Lipoprotein lipase may play a significant role in the distribution of dietary vitamin $\mathrm{E}$ from chylomicrons to tissues. This study documents that lipoprotein lipase can effect a mass transfer of tocopherol from the lipid droplet of chylomicrons or Intralipid to the cells. The increase in the cellular tocopherol content was determined by chemical measurements of the amount of tocopherol present in the cells (either erythrocytes or fibroblasts) following incubation with either chylomicrons or Intralipid 
with the addition of bovine milk lipoprotein lipase. The addition of lipase resulted in the hydrolysis of triglyceride and the transfer of both fatty acids and tocopherol to the cells; no increase in the cellular tocopherol content was noted in the absence of lipase.

The demonstration that lipoprotein lipase itself was the agent transferring tocopherol was made in an incubation system that included only fibroblasts, $4 \%$ BSA in DMEM, and Intralipid (an artificial emulsion containing 10\% soybean oil, which has gamma but not alpha tocopherol). This system has the advantage of containing no apolipoproteins and any tocopherol transferred is gamma, which is usually not present in the fibroblasts. Again, the addition of lipase to this system resulted in the mass transfer of tocopherol (gamma) to the fibroblasts (Fig. 2). Addition of apolipoprotein CII and the lipase to the incubation system resulted in a further increase in the cellular tocopherol content (Table II).

We also demonstrated that the addition of heparin to the incubation system abrogates the transfer of tocopherol to fibroblasts without altering the rate of triglyceride hydrolysis (Fig. 3). Furthermore, in the presence of heparin, apolipoprotein CII added to the incubation system did not restore the transfer of tocopherol to fibroblasts (Table III). Thus, these experiments show that for tocopherol to be transferred to cells during the hydrolysis of triglyceride by lipoprotein lipase, the lipase must bind to the cell membrane as has previously been demonstrated for transfer of cholesteryl ethers (13). We conclude from this data that lipoprotein lipase transfers tocopherol from the lipid droplet to cells. The addition of apolipoprotein CII increases the affinity of lipase for the lipid droplet, thus increasing the amount of tocopherol transferred. As heparin prevents lipoprotein lipase from binding to the cell membrane of fibroblasts, it prevents the transfer of tocopherol.

The present study was undertaken to evaluate the mechanism by which dietary vitamin $E$ is transferred from chylomicrons to tissues. Although the experimental model used was fibroblasts in tissue culture, we have also carried out studies in patients. We have documented that tocopherol levels in adipose tissue can be measured in a needle aspiration biopsy and we have used this measurement of a tissue level of tocopherol to evaluate the adequacy of vitamin E nutriture. We have now analyzed the adipose tissue tocopherol content in more than 100 subjects, both controls and patients with a variety of disorders of lipid metabolism. Although we have reported that the usual level of adipose tissue tocopherol in normal persons, who do not ingest vitamin $E$ supplements, is 200-250 ng tocopherol/mg triglyceride, we have recorded values in abetalipoproteinemic subjects, who have been receiving supplemental vitamin E (400 IU/d) for several years, to be as low as $35 \mathrm{ng}$ tocopherol/mg triglyceride (22). These abetalipoproteinemic subjects do not have neurological abnormalities, but it appears prudent to recommend supplemental vitamin E to achieve adipose tissue tocopherol levels that approach $200 \mathrm{ng}$ tocopherol/mg triglyceride; this is possible in these patients if they take $100-150 \mathrm{mg}$ tocopherol $/ \mathrm{kg} / \mathrm{d}$ in divided doses (1).

Furthermore, the data from these clinical measurements suggests that lipoprotein lipase is the mediator of the transfer of dietary tocopherol to tissues in vivo. The adipose tissue tocopherol content of an 11 -yr-old pubertal girl with lipoprotein lipase deficiency (type 1) was only $59 \mathrm{ng}$ tocopherol/mg triglyceride, a value distinctly lower than the range measured in normal subjects (200-250 $\mathrm{ng}$ tocopherol/mg triglyceride). This adipose tissue value was obtained when the simultaneous measurement of her plasma tocopherol level was a high value of $14 \mu \mathrm{g} / \mathrm{ml}$ (normal values are 7-10 $\mu \mathrm{g} / \mathrm{ml}$ plasma). Previously, Kayden (1) has reported that the adipose tissue tocopherol levels in adult subjects with lipoprotein lipase deficiency were low but within normal range, while plasma levels were more than twice normal. The tocopherol content of the child's plasma, following removal of chylomicrons by ultracentrifugation at $100,000 \mathrm{~g}$ for $1 \mathrm{~h}$, was $2.9 \mu \mathrm{g} / \mathrm{ml}$; as normal individuals do not have chylomicrons present in their plasma, her nonchylomicron, non-VLDL value can be compared with the normal plasma level $(7-10 \mu \mathrm{g} / \mathrm{ml})$. It should be noted that the distribution of tocopherol in lipoproteins of normal subjects is primarily in LDL and HDL (8). We have recently demonstrated that the high affinity receptor for LDL also serves to deliver tocopherol to cells (10). Thus, there appears to be redundant mechanisms for the delivery of both peroxidizable lipids and an antioxidant, tocopherol, to the tissues. In the lipoprotein lipase-deficient child, the low levels of tocopherol in the adipose tissue and in the "LDL and HDL" fraction of the plasma reflect the sharp restriction of dietary fat, which limits the intake of vitamin $\mathrm{E}$. Thus, the adipose tissue of the patient contains a low concentration of tocopherol due to both a low level of tocopherol in the LDL fraction, which limits the ability of the LDL receptor pathway to deliver vitamin $E$ to the tissues, and the inability of the patient to utilize the tocopherol present in the chylomicron and VLDL fraction, which do not easily undergo lipolysis due to the absence of lipoprotein lipase. The data from this child warrants us to recommend oral supplementation with vitamin $E$ for patients with lipoprotein lipase deficiency.

We have also measured the adipose tissue tocopherol content in a patient with a reduced level of LDL receptors. In this adult male (age 46) with the diagnosis of the heterozygous form of hypercholesterolemia (type 2 a), his adipose tissue tocopherol level was $209 \mathrm{ng} \mathrm{E} / \mathrm{mg}$ triglyceride, while his plasma level was $13 \mu \mathrm{g}$ tocopherol $/ \mathrm{ml}$. Although the plasma tocopherol in this patient was elevated, a reflection of the elevated LDL levels, the adipose tissue was at a normal level.

The in vitro studies were carried out to attempt to determine mechanisms involved in the transfer of tocopherol to tissues. The physiological importance of the two pathways is only suggestive at this time; the observations in the patients with various disorders of lipoprotein metabolism do lend credence to our hypotheses that both the lipoprotein lipase pathway and the LDL receptor pathway are important for the delivery of tocopherol to tissues in vivo. From our data it is not possible to extrapolate to give an estimate of the importance of each pathway in vivo. Under the conditions of our studies, using the optimal levels of transfer for each mechanism, the transfer of tocopherol to fibroblasts via the lipoprotein lipase pathway appears to be more than 10-fold the amount transferred via the LDL receptor pathway.

\section{Acknowledgments}

Barbara Miller provided excellent technical assistance. Sandip Parikh and Peter Fumo participated in the development of the experimental protocol.

Support was provided by U. S. Public Health Service grant no. HL30842, the Swedish Medical Research Council (13x-00727), and Hoffmann-La Roche, Nutley, NJ. 


\section{References}

1. Kayden, H. J. 1983. Tocopherol content of adipose tissue from vitamin E-deficient humans. In Biology of Vitamin E. R. Porter, and J. Whelan, editors. Ciba Found. Symp. 101:70-91.

2. Kayden, H. J. 1969. Vitamin E deficiency in patients with abetalipoproteinemia. In Vitamine A, E und $\mathrm{K}$. Klinische und physiologisch-chemische probleme. H. F. von Kress, and K. U. Blum, editors. Symposion, veranstaltet von der I. Medizinischen Klinik der Freien Universitat Berlin 1967. F. K. Schattauer Verlag, Stuttgart. 301-308:

3. Guggenheim, M. A., S. P. Ringle, A. Silverman, B. E. Grabert, and H. E. Nevil. 1982. Progressive neuromuscular disease in children with chronic cholestasis and vitamin E deficiency: clinical and muscle biopsy findings and treatment with alpha tocopherol. Ann. NY Acad. Sci. 393:84-93.

4. Howard, L., L. Ouesen, S. Satya-Murti, and R. Chu. 1982. Reversible neurologic symptoms caused by vitamin $\mathrm{E}$ deficiency in a patient with short bowel syndrome. Am. J. Clin. Nutr. 36:1243-1249.

5. Muller, D. P. R., J. K. Lloyd, and O. H. Wolff. 1983. Vitamin $\mathrm{E}$ and neurological function: abetalipoproteinaemia and other disorders of fat absorption. In Biology of Vitamin E. R. Porter and J. Whelan, editors. Ciba Found. Symp. 101:106-121.

6. Rosenblum, J. L., J. P. Keating, A. P. Prensky, and K. S. Nelson. 1981. A progressive, disabling, neurologic syndrome in children with chronic liver disease: a possible result of vitamin E deficiency. $N$. Engl. J. Med. 304:503-508.

7. Sokol, R. J., J. E. Heubi, S. T. Iannaccone, K. E. Bove, and W. F. Balistreri. 1983. Mechanism causing vitamin E deficiency during chronic childhood cholestasis. Gastroenterology. 85:1172-1182.

8. Bjornson, L. K., H. J. Kayden, E. Miller, and A. N. Moshell. 1976. The transport of alpha tocopherol and beta carotene in human blood. J. Lipid Res. 17:343-352.

9. Kayden, H. J., and L. K. Bjornson. 1972. The dynamics of vitamin E transport in the human erythrocyte. Ann. NY Acad. Sci. 203:127-140.

10. Traber, M. G., and H. J. Kayden. 1984. Vitamin E is delivered to cells via the high affinity receptor for low density lipoprotein. $\mathrm{Am}$. J. Clin. Nutr. 40:747-751.
11. Nelsson-Ehle, P., A. S. Garfinkel, and M. C. Schotz. 1980. Lipolytic enzymes and plasma lipoprotein metabolism. Ann. Rev. Biochem. 49:667-693.

12. Fielding, C. J. 1978. Metabolism of cholesterol-rich chylomicrons. Mechanism of binding and uptake of cholesteryl esters by the vascular bed of the perfused rat heart. J. Clin. Invest. 62:141-151.

13. Chajek-Shaul, T., G. Friedman, O. Stein, T. Olivecrona, and Y. Stein. 1982. Binding of lipoprotein lipase to the cell surface is essential for the transmembrane transport of chylomicron cholesteryl ester. Biochim. Biophys. Acta. 712:200-210.

14. Kayden, H. J., C. K. Chow, and L. Bjornson. 1973. Spectrophotometric method for determination of tocopherol in red blood cells. J. Lipid Res. 14:533-540.

15. Bengtsson, G., and T. Olivecrona. 1977. Interaction of lipoprotein lipase with heparin-Sepharose. Evaluation of conditions for affinity binding. Biochem. J. 167:109-119.

16. Bengtsson, G., and T. Olivecrona. 1982. On the pH dependency of lipoprotein lipase activity. Biochim. Biophys. Acta. 712:196-199.

17. Traber, M. G., and H. J. Kayden. 1980. Low density lipoprotein receptor activity in human monocyte derived macrophages and its relation to atheromatous lesions. Proc. Natl. Acad. Sci. USA. 77:54665470 .

18. Lowry, O. H., M. J. Rosebrough, A. L. Farr, and R. J. Randall. 1951. Protein measurement with the folin phenol reagent. J. Biol. Chem. 193:265-275.

19. Hatam, L. J., and H. J. Kayden. 1979. A high-performance liquid chromatographic method for the determination of tocopherol in plasma and cellular elements of the blood. J. Lipid Res. 20:639645 .

20. Belfrage, P., and M. Vaughan. 1969. Simple liquid-liquid partition system for isolation of labeled oleic acid from mixtures with glycerides. J. Lipid Res. 10:341-344.

21. Stern, E., and Shapiro, B. 1953. A rapid and simple method for the determination of esterified fatty acids and for total fatty acids in blood. J. Clin. Pathol. (Lond.). 6:158-160.

22. Kayden, H. J., L. J. Hatam, and M. G. Traber. 1983. The measurement of nanograms of tocopherol from needle aspiration biopsies of adipose tissue: normal and abetalipoproteinemic subjects. J. Lipid Res. 24:652-656. 